\title{
CONGESTION MANAGEMENT BY OPTIMAL ALLOCATION OF FACTS CONTROLLERS USING HYBRID FISH BEE OPTIMIZATION
}

\author{
${ }^{1}$ S. Thangalakshmi and ${ }^{2} \mathbf{P}$. Valsalal \\ ${ }^{1}$ Department of Electrical and Electronics Engineering, \\ GKM College of Engineering and Technology, Chennai, India \\ ${ }^{2}$ Department of Electrical and Electronics Engineering, \\ Anna University, CEG Campaus, Chennai, India
}

Received 2014-01-18; Revised 2014-03-03; Accepted 2014-04-24

\begin{abstract}
The role of Independent System Operator (ISO) in the restructured power industry includes system control, capacity planning, transmission tariff and congestion management; the challenging task being minimizing the congestion. One of the popular techniques used to alleviate congestion is using Flexible AC Transmission Systems (FACTS) devices. The power system generally operates near its rated capacity in deregulated market because of intensive usage of transmission grids. So, the major issues that need to be addressed are improving the voltage profile and reducing the power loss in the electrical network. Motivation: The location of FACTS devices can improve the power flow in the line, maintain the bus profile and reduce the losses. However locating the ideal location is a NP problem. This study presents a novel heuristic method to determine the types of FACTS devices and its optimal location in a power system without violating the thermal and voltage limits. Power flow sensitivity index to find the optimal location of UPFC is suggested in this study. A hybrid fish bee swarm optimization is proposed which is based on Artificial Bee Colony (ABC) and Fish School Search (FSS) methods. This proposed algorithm is tested based on IEEE 30 bus system and line performances are studied.
\end{abstract}

Keywords: Congestion Management, ISO, FACTS, Power Flow Sensitivity Index, UPFC, Hybrid Optimization, Artificial Bee Colony (ABC), Fish School Search (FSS)

\section{INTRODUCTION}

In a competitive power market, the system is congested when the amount of power transactions is beyond the transfer capability of the transmission line and the lines are forced to operate closer to thermal limits. Congestion is due to lines reaching thermal limits and/or voltage limits. If such heavy power flow is not controlled, few of the lines are overloaded and may lead to emergency system operating state. The challenging task in the deregulated power system is to provide a transmission network which delivers contracted power from suppliers to consumers under controlled market forces, with frequently varying demand and supply. One of such methods of managing congestion is using a proper FACTS device in congested line.

Flexible AC Transmission Systems (FACTS) are being widely used due to their capability to enhance power system performance. The FACTS controllers employ power electronics based technology. They are used to reduce transmission line congestion and helps in better utilization of existing grid structure. These devices permit system operator to control power flow by improving the line transfer capability without violating thermal limits. Also, they have flexibility to control voltage, active and reactive power simultaneously. The reduction of power

Corresponding Author: Thangalakshmi, S., Department of Electrical and Electronics Engineering,

GKM College of Engineering and Technology, Chennai, India 
flow in heavily loaded lines results in increased loadability, low power loss, improved network stability and reduced production cost. Transmission system owners and operators prefer FACTS devices to manage the power transfer because of the above qualities.

The FACTS controllers have been broadly developed based on two different principles. First principle is either altering the line series reactance or bus shunt reactance or voltage phase difference across a line by using conventional thyristor switches for control (Kumkratug, 2011). Commonly used switches are Static VAR Compensator (SVC) and Thyristor Controlled Series Compensator (TCSC). The second principle is to control the series injected voltage and/or shunt injected current with employing voltage source converters. Among two principles, SVC and Static Synchronous Compensator (STATCOM) are the shunt compensators, whereas, TCSC and Static Synchronous Series Compensator (SSSC) are the series compensators. The Unified Power Flow Controller (UPFC) combines both series and shunt compensators and offers more versatile characteristics than other controllers.

There are many research papers available in literature regarding congestion management using FACTS devices. A combination of Demand Response (DR) and FACTS devices was proposed for congestion management using two-step market clearing procedure (Yousefi et al., 2012).

Acharya et al. (2005) discussed the development of FACTS devices and collection of major FACTS installations. Various issues and a detailed cost analysis related to FACTS devices were presented. The problem of high losses and coordination among various controllers had been analyzed. FACTS devices were used to solve power system steady state control problems like:

- Voltage regulation

- Power flow control and

- Enhanced transfer capability

Damping inter-area modes and power system stability enhancement with FACTS controllers were studied and investigated as supplementary functions. The use of FACTS devices in managing power system congestion would be effective depending upon their location.

The location of FACTS devices would impose substantial impact on the market participants directly or indirectly because of their high cost (Sode-Yome and Mithulananthan, 2004; Srivastava and Verma, 2000).
Locational Marginal Pricing (LMP) difference method and congestion rent contribution method were proposed to find the best location for TCSC. A sensitivity factor method analysis was also provided (Acharya and Mithulananthan, 2007). The increase in LMP was taken into account to measure the degree of congestion and there by potential locations for FACTS devices were identified.

The technical and economic issues in using FACTS devices for congestion management were proposed by Mwanza and Shi (2007). A method based on constrained generator rescheduling was considered. It was verified that including FACTS devices for congestion management would extensively reduce the rescheduling power. A new electrical dissecting method was proposed for the use of phase-shifter in relieving congestion (Tang et al., 2007). The responsible factors of consumers and suppliers causing congestion were obtained using the proposed method.

Impact of renewable energy specifically wind generation on electricity network in congestion management and related challenges were presented by Zhang and Yao (2008). It was recognized that applications of FACTS and HVDC technologies with wide area measurement system were cost effective. A Dynamic Power Flow Controller (DPFC) was introduced with control scheme and coordination method by Rehtanz and Hager (2008) for congestion management. Simulations determined that the transfer capability reached with DPFC was effective than the phase-shifting method.

A novel optimization-based method for placement of FACTS devices to relieve congestion using TCSC and SVC in transmission lines was investigated by Gitizadeh and Kalantar (2008). The objective also focused on increasing static security margin and voltage profile of a power system. Optimizations were carried out based on location, size and number of FACTS devices. A method to determine optimal location of TCSC was suggested by Mandala and Gupta (2010). The environmental and cost problems were taken into account to meet the objective.

Joorabian et al. (2011) used TCPST in congestion management. A method based on locational marginal price and optimal power flow in combination with TCPST was used for optimal setting and to determine appropriate location for management/reduction of transmission lines congestion in restructured environment. Shi and Mwanza (2007) handled congestion problems in combined pool and bilateral contract markets using re-dispatch method and suggested a solution for optimal operating point. 
The proposed paper suggests a hybrid algorithm to find optimal location of UPFC to minimize transmission line congestion in competitive power market.

\section{UPFC IN CONGESTION MANAGEMENT}

An Based on the connection in the network, FACTS controllers are broadly classified into four categories viz. Series controllers, Shunt Controllers, Combined Series-Series Controllers and Combined Series-Shunt Controllers. The combined series-shunt controllers are a combination of separate shunt and series controllers. In principle, combined shunt and series controllers inject current into the system with the shunt part of the controller and voltage in the line with the series part of the controller. There can be a real power exchange between the series and shunt controllers via a DC link when the shunt and series controllers are controlled in a unified manner. Unified Power Flow Controller (UPFC) is one of the series shunt controllers.

In this study the optimal location of UPFC is investigated. The UPFC provides simultaneous control of all basic power system parameters such as transmission voltage, impedance and phase angle. The controller can fulfill functions of reactive shunt compensation, series compensation and phase shifting to accomplish multiple control objectives. From a functional perspective, the objectives are met by applying a boosting transformer injected voltage and an exciting transformer reactive current. The injected voltage is inserted by a series transformer. Besides transformers, the general structure of UPFC contains a "back to back" AC to DC voltage source converters operated from a common DC link capacitor as shown in Fig. 1.

First converter (CONV1) is connected in shunt and the second one (CONV2) in series with the line. The shunt converter is used to provide an active power demand of the series converter through a common DC link. Also converter 1 generates or absorbs the reactive power, if it is desired and thereby provide independent shunt reactive compensation for the line. Converter 2 provides the main function of the UPFC by injecting a voltage with controllable magnitude and phase angle in series with the line via a voltage source as shown in Fig. 2.

The reactance $x$ s describes a reactance seen from terminals of the series transformer and is equal to:

$$
x_{S}=x_{k} r_{\max }^{2}\left(\frac{S_{B}}{S_{S}}\right)
$$

Where:

$\mathrm{x}_{\mathrm{k}}=$ The series transformer reactance

$r_{\max }=$ The maximum per unit value of injected voltage magnitude

$\mathrm{S}_{\mathrm{B}}=$ The system base power and

$\mathrm{S}_{\mathrm{S}}=$ The nominal rating power of the series converter

The UPFC injection model is derived enabling three parameters to be simultaneously controlled.

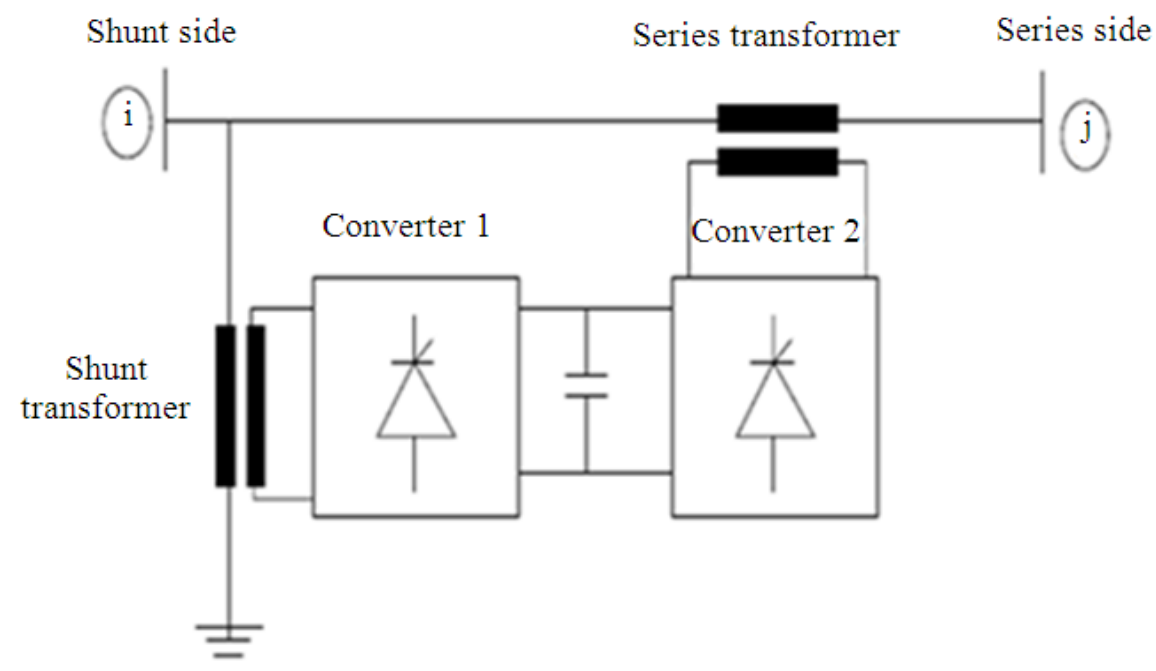

Fig. 1. Implementation of the UPFC by back-to-back voltage source converters 


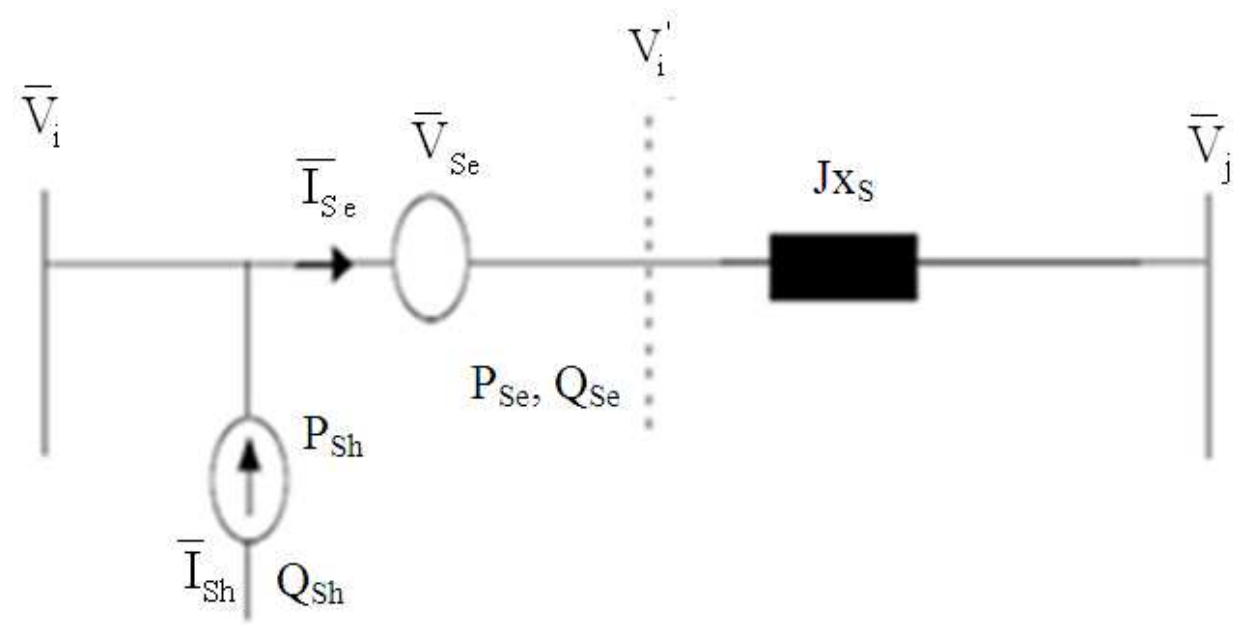

Fig. 2. The UPFC electric circuit arrangements

They are named as the:

- $\quad$ Shunt reactive power $\left(\mathrm{Q}_{\text {conv1 }}\right)$

- Magnitude (r) and

- Angle $(\gamma)$ of injected series voltage

The series connected voltage source is modeled by an ideal series voltage which is controllable in magnitude and phase, that is:

$$
\mathrm{V}_{\mathrm{Se}}=\mathrm{rV}_{\mathrm{k}} \mathrm{ey}
$$

Where:

$$
0 \leq \mathrm{r} \leq \mathrm{r}_{\max } \text { and } 0 \leq \gamma \leq 2 \pi
$$

The congestion is relieved in transmission lines using SVC and UPFC (Singh and Verma, 2011). They suggested that global optimal solution could be obtained effectively using GA. The optimal location and rating of the STATCOM for congestion management using power world simulator software was proposed by (Sneha and Vedashree, 2013).

An optimization methodology was provided by Chong et al. (2007) for finding the optimal rating of the UPFC located at congested transmission line. The study suggested a general two step methodology to maximize the benefits of a UPFC controller in a bilateral market. An economic comparison was done between congestion cost and installation cost of a UPFC during heavily loaded conditions. It is inferred from the literature that optimal location of FACTS devices is paramount in minimizing congestion. There are many algorithms available for finding the optimal location of these devices.

In this research work a new algorithm is proposed to find the optimal location of UPFC controller. The proposed Hybrid Fish Bee Swarm Optimization is based on Artificial Bee Colony (ABC) and Fish School Search (FSS) methods. The first step in locating UPFC is the identification of highly congested line. The power flow Performance Index (PI) serves the purpose.

\section{SIGNIFICANCE OF POWER FLOW PERFORMANCE INDEX (PI)}

The process of installing FACTS devices is considerably important in the determination of type, location and rating of the equipment because of their relatively high cost. Optimal location is based on real power PI and on total system active power and reactive power losses reduction. Many literatures have proved that location of FACTS devices is a predominant factor. The optimal location of FACTS devices centers in finding the most congested line. Hence, a factor for finding the severity of line congestion is used to determine the most congested line. The severity of the system loading under normal and contingency cases is explained by a real power flow performance index:

$$
\mathrm{PI}=\sum_{\text {all branchesi }}\left(\frac{\mathrm{P}_{\text {flow } 1}}{\mathrm{P}_{1}^{\max }}\right)^{2 \mathrm{n}}+\sum_{\text {all branchesi }}\left(\frac{\Delta\left|\mathrm{E}_{1}\right|}{\Delta\left|\mathrm{E}_{1}\right|^{\max }}\right)^{2 \mathrm{~m}}
$$


Where:

PI $\quad=$ Performance Index.

$\mathrm{P}_{\text {flow1 }}=$ Real power flow in the line

$\mathrm{P}_{1}{ }^{\max }=$ Maximum power limit

$\mathrm{E}_{\mathrm{i}}{ }^{\max }=$ Line voltage

$\mathrm{E}_{\mathrm{i}}^{\max }=$ Maximum voltage limit

Congestion occurs in the line when voltage and thermal limits are violated. Hence, during overload or congestion the PI value would be high. Thus, it can be inferred that the line having highest PI is the optimum or best location of UPFC. Many algorithms are available for location of FACTS devices. Few of them are dealt here.

\subsection{Existing Algorithms}

The following literatures gave basic idea about the optimization techniques employed for congestion management using FACTS devices.

Single and multi-objective optimization approaches for optimal choice, location and size of SVC and TCSC in deregulated power system to improve branch loading and voltage stability and reducing line losses was presented by Reddy et al. (2010). Optimal FACTS controllers' location considering branch loading, voltage stability and loss minimization were presented as objectives using GA.

The concept of voltage stability index was proposed by Wibowo et al. (2009). A multi objective Particle Swarm Optimization was used to optimize generation and installation cost. A PSO based algorithm to locate series FACTS devices in deregulated electricity markets to reduce/manage congestion was proposed by Hashemzadeh and Hosseini (2009). Line outage sensitivity factors reduced solution space and pinpointed lines suitable for FACTS device placement. Muthukrishnan et al. (2014) compared the effectiveness of GA, Enhanced GA (EGA) and PSO for finding the optimal locations of FACT in transmission lines.

A new GA to find optimal location and size of TCSC for congestion management was proposed by Hosseinipoor and Nabavi (2010). Rahim et al. (2010) proposed a congestion management problem using bee colony optimization where the aim of the proposed study was optimizing generation cost in power system network with given constraints.

Since the proposed algorithm is the combination of Artificial Bee Colony algorithm (ABC) and Fish School Swarm Intelligence algorithm (FSS), a brief discussion of them is given in the following section.

\subsection{Artificial Bee Colony Algorithm (ABC)}

The use of Artificial Bee Colony algorithm (ABC) for various applications had been discussed in (Balasubramani and Marcus, 2013; Baykasoglu et al., 2007; Karaboga and Ozturk, 2011). Actual position of a food source in $\mathrm{ABC}$ algorithm corresponds to a solution to optimization problem with the nectar found in a food source representing the associated solution's quality. The number of employed bees and onlooker bees are equal and so also with food sources number. Each employed bee is assigned an individual food source. This algorithm is an iterative process that starts by initializing all employed bees with food sources randomly generated i.e., solution represented by a D-dimensional real valued vector. Every employed bee for each iteration finds food source in neighbourhood of current food source and evaluates nectar amount i.e., fitness (Balasubramani and Marcus, 2013; Baykasoglu et al., 2007).

The algorithm's main steps are:

- Send employed bees to food sources and determines the nectar amounts

- Calculates source probability value with preferrence of onlooker bees

- Stop exploitation process of sources is abandoned by bees

- Send scouts to search area randomly to discover new food sources

- Memorize best food source found

An artificial bee colony consists of three groups of bees in this algorithm: Employed bees, onlookers and scouts (Liu, 2013). A bee waiting on dance floor to make a decision to choose food source is called onlooker and one going to food source visited by it earlier is an employed bee. The other bee is scout bee that carries out random search to discover new sources. Food source position represents a possible solution for optimization problem and nectar in a food source which corresponds to fitness of an associated solution and is calculated by:

$$
\text { fit }_{i}=\frac{1}{1+f_{i}}
$$

Generally the algorithmic structure of the ABC optimization approach is given as follows:

- Initialization phase

- Employed bees phase

- Onlooker bees phase 
- Scout bees phase

- Memorize the best solution achieved so far and

- $\quad$ UNTIL (Cycle = Maximum Cycle Number or a Maximum CPU time)

In initialization phase, population of food sources are initialized by artificial scout bees with control parameters being set. Artificial employed bees search for new food sources having more nectar in food source neighbourhood, in their memory, in employed bees phase. In the onlooker bee's phase, artificial onlooker bees probabilistically choose food sources based on information provided by employed bees. In scout bee's phase, employed bees solutions which cannot be improved by predetermined trials, called "limit", become scouts with their solutions being abandoned.

\section{MATERIALS AND METHODS}

From literature it is seen that existing evolutionary algorithms either converge slowly or face the problem of local minima. This work overcomes the issues faced by proposing an hybrid algorithm. The proposed algorithm is a hybrid fish bee optimization algorithm to ensure an effective/competent solution by integrating advantages of both the above algorithms to make search efficient, especially when a problem has many solutions. The flowchart of the proposed hybrid optimization is shown in Fig. 3. The optimal location of the UPFC device is based on the branch loading, deviation in voltage and the efficient utilization of line capacity.

The previous section discusses the bee algorithms. The use of Fish School Swarm Intelligence algorithm (FSS) for various applications had been discussed in (Liu, 2013; Fernandes et al., 2009; Rocha et al., 2012). An optimizing method based on autonomous animates, Artificial Fish Swarm Algorithm, was developed by Chinese scholars, Li et al. (2004), imitating fish behavior. The basic idea (Liu, 2013) of Artificial Fish-swarm Algorithm is as follows. In waters, where most fish are gathered, there is abundant food. According to this fish characteristic, artificial fish are constructed and let to imitate preying, swarming, following and other acts. Each artificial fish corresponds to an optimal solution and virtual waters, where artificial fish survive corresponds to solution space of optimization problem and food concentration corresponds to objective function value. Thus, optimal solution is obtained (Fernandes et al., 2009).

The main fish swarm behaviors are as follows:
- Random behavior: Generally fish swim randomly looks for food and other companions.

- Searching behavior: This is basic biological behavior as fish tend to go to food; when fish discover a region with more food, by vision/sense, they go to it directly/quickly.

- Swarming behavior: While swimming, fish assemble in groups. This is a habit to guarantee existence of swarm and to avoid dangers.

- Chasing behavior: When a fish or a group in the swarm discovers food then, others in neighborhood finds food dangling quickly after it.

The objective function is given by:

$$
\text { Minimize: } \alpha \text { (Branch loading factor) }+\beta \text { (Line }
$$
utilization factor $\times$ Voltage deviation)

\section{RESULTS}

The proposed method is tested using IEEE 30 bus system. The proposed fitness function tries to find an optimal solution for the location of UPFC by minimizing the Branch loading and improving voltage stabilization. To study the proposed technique, congestion is created in the lines by uniformly over loading the system by $30 \%$. The ten largest power flow sensitivity values in the IEEE 30 bus system is shown in Table 1. Power flow sensitivity index

Based on the sensitivity index UPFC were placed in lines 1-3 and lines 3-4. The overloading in each line before and after placement of UPFC is shown in Fig. 4. Based on the results it is found that the congestion is reduced by locating UPFC. It is evident from Fig. 4 and 5 that the fitness function not only identifies the optimal location of UPFC but also enables congestion management by distributing the load to reduce overall congestion

Table 1. Power flow sensitivity index

\begin{tabular}{ll}
\hline Lines & $\begin{array}{l}\text { Power flow } \\
\text { sensitivity index }\end{array}$ \\
\hline $1-3$ & 8.12 \\
$3-4$ & 7.96 \\
$2-4$ & 6.45 \\
$2-5$ & 6.18 \\
$2-6$ & 3.85 \\
$4-6$ & 3.64 \\
$5-7$ & 0.94 \\
$6-8$ & 0.93 \\
$8-28$ & 0.85 \\
$2-15$ & 0.81 \\
\hline
\end{tabular}




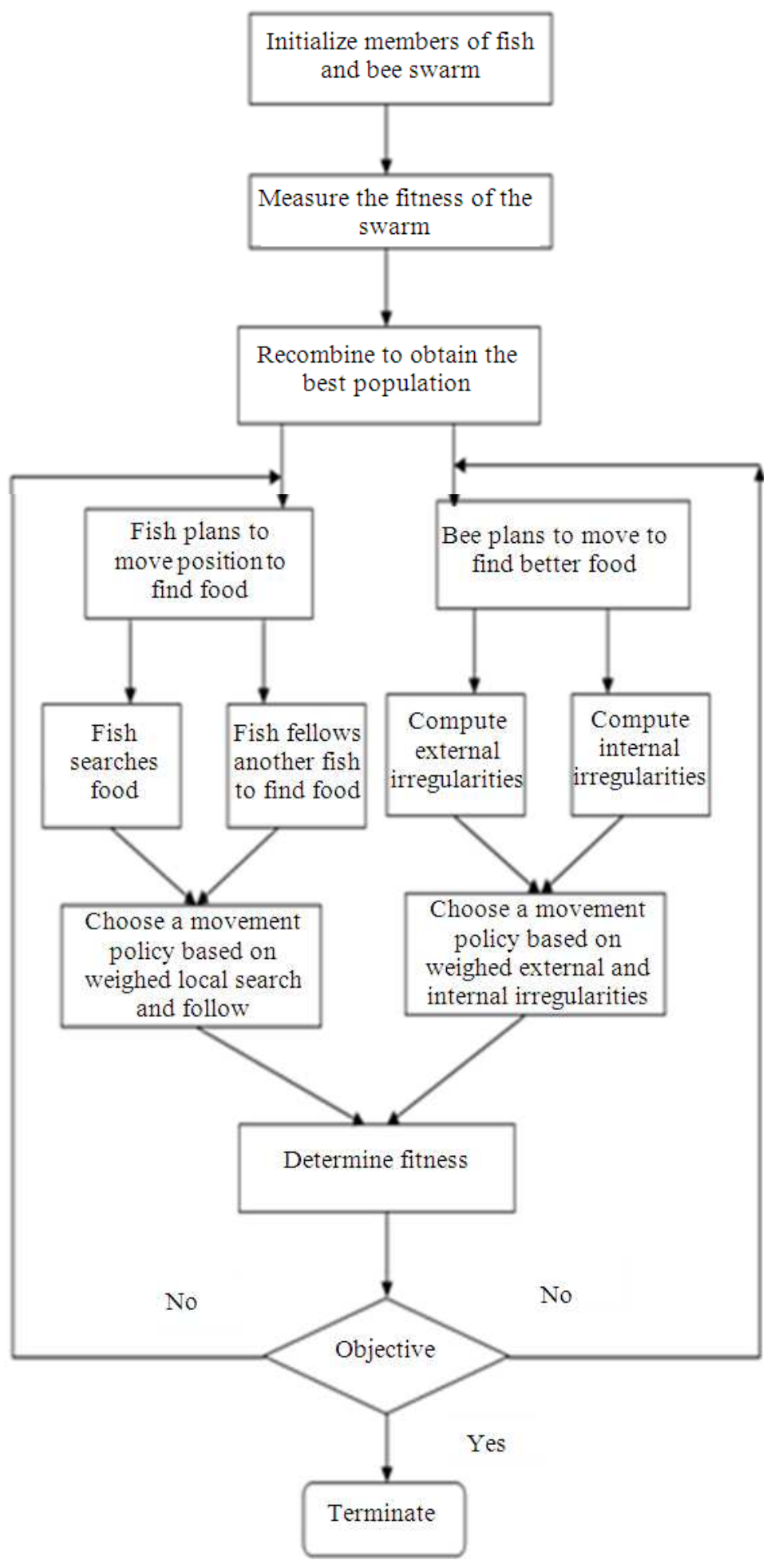

Fig. 3. A hybrid fish bee swarm optimization 


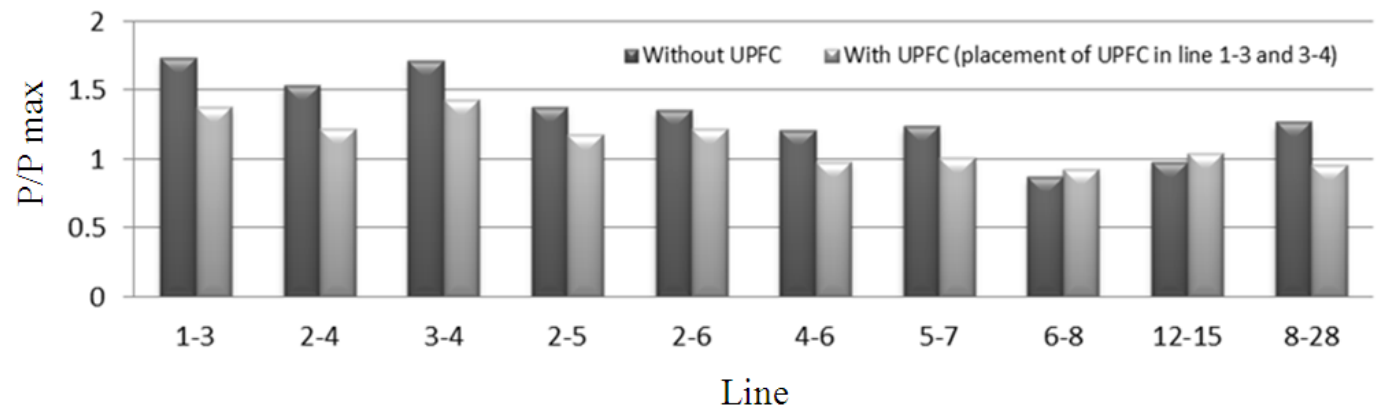

Fig. 4. Line loading-heavily congested lines

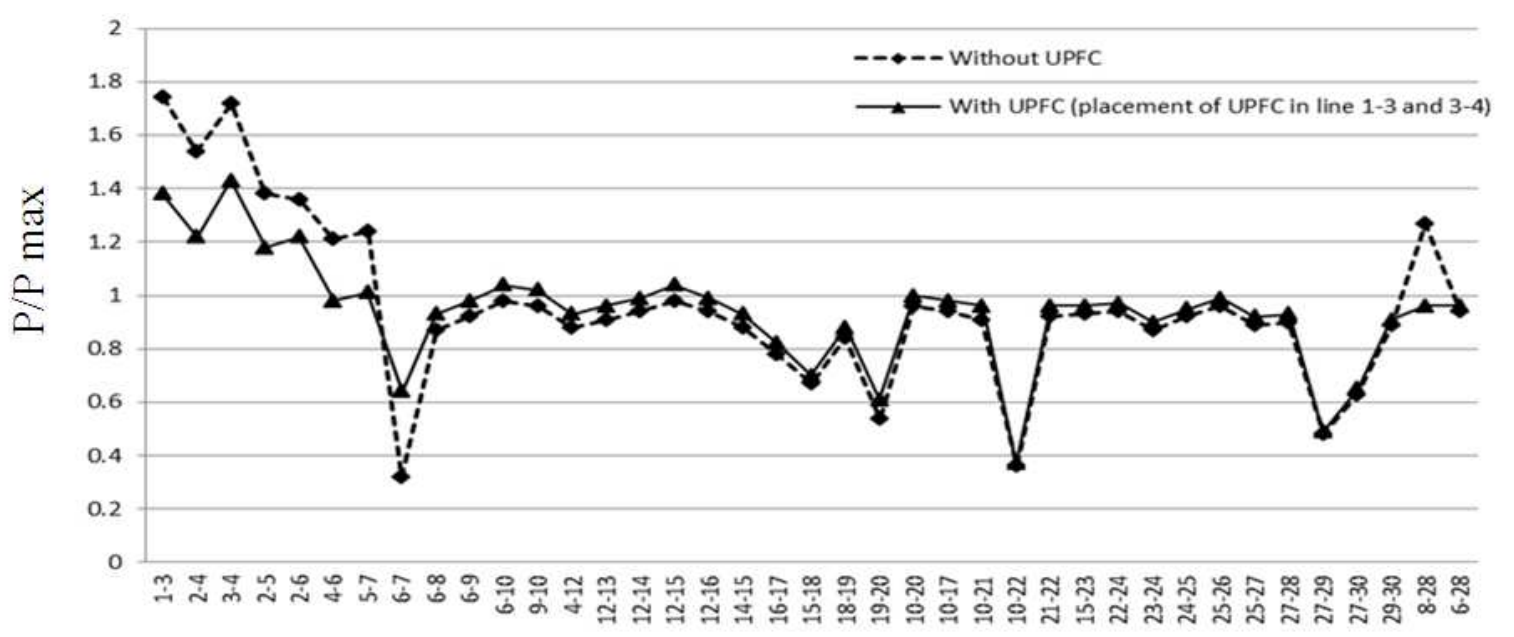

Line

Fig. 5. Line loading

\section{DISCUSSION}

From Fig. 5 it can be observed that congestion is relieved by more than $5 \%$ in atleast 10 lines. The maximum congestion relief is obtained in line 1-3 with relief of over $27 \%$. Lines $10-22$ had the minimum relief compared to all other lines as seen in Fig. 5.

\section{CONCLUSION}

More attention is given to FACTS devices applications in power systems as they proved to be good solution for varied power system problems. A pertinent FACTS application related issue is selection of appropriate location. Proper location maximizes the benefits of expensive FACTS devices. FACTS devices like UPFC by controlling network power flow reduce congestion in heavily loaded lines. Due to the high costs of FACTS devices, optimal location for placement of these devices is mandatory. The new hybrid algorithm converged to maximum without being trapped at local optima for optimal choice and FACTS controller's location. The power transfer capability is enhanced by $22.44 \%$ in highly congested lines (when the system is uniformly overloaded by $30 \%$ ) after placing UPFC in lines $1-3$ and $3-4$. It is concluded that location of UPFC plays a significant role in congestion management.

\section{REFERENCES}

Acharya, N. and N. Mithulananthan, 2007. Locating series FACTS devices for congestion management in deregulated electricity markets. Elec. Power Syst. Res., 77: 352-360. DOI: 10.1016/j.epsr.2006.03.016 
Acharya, N., A. Sode-Yome and N. Mithulananthan, 2005. Facts about Flexible AC Transmission Systems (FACTS) controllers: Practical installations and benefits. Proceedings of the Australasian Universities Power Engineering Conference, Sep. 25-28, School of Engineering, University of Tasmania, Tasmania, Australia, pp: 533-538.

Balasubramani, K. and K. Marcus, 2013. A comprehensive review of artificial bee colony algorithm. Int. J. Comput. Tech., 5: 15-28.

Baykasoglu, A., L. Ozbakir and P. Tapkan, 2007. Artificial bee Colony Algorithm and its Application to Generalized Assignment Problem. In: Swarm Intelligence: Focus on Ant and Particle Swarm Optimization, Felix, T.S., Chan and M.K. Tiwari (Eds.), Tech Education and Publishing ISBN-10: 3902613092, pp: 113-144.

Chong, B., X.P. Zhang, K.R. Godfrey, L. Yao and M. Bazargan, 2007. Congestion management of electricity markets using FACTS controllers. Proceedings of the IEEE Power Engineering Society General Meeting, Jun. 24-28, IEEE Xplore Press, Tampa, FL., pp: 1-6. DOI: 10.1109/PES.2007.386122

Fernandes, E.M.D.G., T.F. Martins and A.M.A., Rocha, 2009. Fish swarm intelligent algorithm for bound constrained global optimization. Proceedings of the International Conference on Computational and Mathematical Methods in Science and Engineering, Jun. 30-Jul. 3, Gijón, Spain.

Gitizadeh, M. and M. Kalantar, 2008. A new approach for congestion management via optimal location of FACTS devices in deregulated power systems. Proceedings of the 3rd International Conference on Electric Utility Deregulation and Restructuring and Power Technologies, Apr. 6-9, IEEE Xplore Press, Nanjuing, pp: 1592-1597. DOI: 10.1109/DRPT.2008.4523659

Hashemzadeh, H. and S.H. Hosseini, 2009. Locating series FACTS devices using line outage sensitivity factors and particle swarm optimization for congestion management. Proceedings of the IEEE Power and Energy Society General Meeting, Jul. 26-30, IEEE Xplore Press, Calgary AB., pp: 1-6. DOI: 10.1109/PES.2009.5275773
Hosseinipoor, N. and S.M. Nabavi, 2010. Optimal locating and sizing of TCSC using genetic algorithm for congestion management in deregualted power markets. Proceedings of the Environment and Electrical Engineering (EEEIC), Proceedings of the 9th International Conference, May 16-19, Prague, Czech Republic, pp: 136-139. 10.1109/EEEIC.2010.5489968

Joorabian, M., M. Saniei and H. Sepahvand, 2011. Optimal locating and sizing of TCPST for congestion management in deregulated electricity markets. Proceedings of the46th International Universities' Power Engineering Conference, Sept. 5-8, IEEE Xplore Press, Soest, Germany, pp: 1-6.

Karaboga, D. and C. Ozturk, 2011. A novel clustering approach: Artificial Bee Colony (ABC) algorithm. Appl. Soft Comput., 11: 652-657. DOI: 10.1016/j.asoc.2009.12.025

Kumkratug, P., 2011. Coordination of series and shunt flexible alternating current transmission line system devices based thyristor controller for improving power system stability. Am. J. Applied Sci., 8: 355358. DOI: 10.3844/ajassp.2011.355.358

Li, X., F. Lu, G. Tian and J. Qian, 2004. Studies on artificial fish swarm optimization algorithm based on decomposition and coordination techniques. J. Shandong Univ.

Liu, N., 2013. An improved artificial fish-swarm algorithm based optimization method for city taxi scheduling system. J. Comput. Inform. Syst., 9: 6351-6359.

Mandala, M. and C.P Gupta, 2010. Congestion management by optimal placement of FACTS device. Proceedings of the Joint International Conference on Power Electronics Drives and Energy Systems Power India, Dec. 20-23, IEEE Xplore Press, New Delhi, pp: 1-7. DOI: 10.1109/PEDES.2010.5712387

Muthukrishnan, J.K., S.S. Dash, H.K. Selvakumar, S. Chinnamuthu and P. Panjamoorthy, 2014. Comparison of optimization technique to find the optimal location of facts controllers for transmission line. Am. J. Applied Sci., 11: 280-290. DOI: 10.3844/ajassp.2014.280.290

Mwanza, K. and Y. Shi, 2007. Economic evaluation of FACTS for congestion management in pool Markets. Proceedings of the IEEE Power Technology, Jul. 1-5, IEEE Xplore Press, Lausanne, Switzerland, pp: 2053-2058. DOI: 10.1109/PCT.2007.4538634 
Rahim, M.A., I. Musirin, I.Z. Abidin, M.M. Othman and D. Joshi, 2010. Congestion management based optimization technique using bee colony. Proceedings of the 4th International Power Engineering and Optimization Conference, Jun.23-24, IEEE Xplore Press, Shah Alam, pp: 184-188. DOI: 10.1109/PEOCO.2010.5559247

Reddy, S.S., M.S. Kumari and M. Sydulu, 2010. Congestion management in deregulated power system by optimal choice and allocation of facts controllers using multi-objective genetic algorithm. Proceedings of the IEEE PES Transmission and Distribution Conference and Exposition, Apr. 19-22, IEEE Xplore Press, New Orleans, $\quad$ pp: 1-7. DOI: 10.1109/TDC.2010.5484520

Rehtanz, C. and U. Hager, 2008. Coordinated wide area control of FACTS for congestion management. Proceedings of the 3rd International Conference on Electric Utility Deregulation and Restructuring and Power Technologies, Apr. 6-9, IEEE Xplore Press, Nanjuing, pp: 130-135. DOI: 10.1109/DRPT.2008.4523390

Rocha, A.M.A., M.F.P. Costa and E.M. Fernandes, 2012. An artificial fish swarm filter-based method for constrained global optimization. Proceedings of the 12th International Conference, Computational Science and Its Applications, Jun. 18-21, Springer Berlin Heidelberg, Brazil, pp: 5771. DOI: 10.1007/978-3-642-31137-6_5

Shi, Y. and K. Mwanza, 2007. Valuation of FACTS for managing congestion in combined pool and bilateral markets. Proceedings of the IEEE Power Engineering Society Conference and Exposition in Africa, Jul. 6-20, IEEE Xplore Press, Johannesburg, $\quad$ pp: 1-7. DOI: 10.1109/PESAFR.2007.4498031

Singh, D. and K.S Verma, 2011. GA-based congestion management in deregulated power system using FACTS devices. Proceeding of the IEEE International Conference and Utility Exhibition on Power and Energy Systems, Sept. 28-30, IEEE Xplore Press, Pattaya City, pp: 1-6. DOI: 10.1109/ICUEPES.2011.6497716

Sneha, T. and R. Vedashree, 2013. Improvement in congestion management with reduction in operating cost in power system using STATCOM controller. Int. J. Eng. Res. Tech.
Sode-Yome, A. and N. Mithulananthan, 2004. Comparison of shunt capacitor, SVC and STATCOM in static voltage stability margin enhancement. Int. J. Elect. Eng. Educ., 41: 158171.

Srivastava, S.C. and R.K. Verma, 2000. Impact of FACTS devices on transmission pricing in a deregulated electricity market. Proceedings of the International Conference on Electric Utility Deregulation and Restructuring and Power Technologies, Apr. 4-7. IEEE Xplore Press, London, pp: 642-648. DOI: 10.1109/DRPT.2000.855741

Tang, Y., F. Yuan and Q.L. Wan, 2007. A new method for assessing ancillary service of FACTS in congestion management. Proceedings of the IEEE Power Engineering Society General Meeting, Jun. 24-28, IEEE Xplore Press, Tampa, FL., pp: 1-7. DOI: 10.1109/PES.2007.385578

Wibowo, R.S., N. Yorino, M. Eghbal, Y. Zoka and Y. Sasaki, 2009. FACTS devices allocation for congestion management considering voltage stability by means of MOPSO. Proceedings of the Transmission and Distribution Conference and Exposition, Asia and Pacific, Oct. 26-30, IEEE Xplore Press, Seoul, pp: 1-4. DOI: 10.1109/TDASIA.2009.5357015

Yousefi, A., T.T. Nguyen, H. Zareipour and O.P. Malik, 2012. Congestion management using demand response and FACTS devices. Int. J. Elect. Power Energy Syst., 37: 78-85. DOI: 10.1016/j.ijepes.2011.12.008

Zhang, X.P. and L. Yao, 2008. A vision of electricity network congestion management with FACTS and HVDC. Proceedings of the IEEE 3rd International Conference on Electric Utility Deregulation and Restructuring and Power Technologies, Apr. 6-9, IEEE Xplore Press, Nanjuing, pp: 116-121. DOI: 10.1109/DRPT.2008.4523388 